\title{
The interplay between musical and linguistic aptitudes: a review
}

\author{
Riia Milovanov ${ }^{1,2,3,4}$ * and Mari Tervaniemi ${ }^{3,5,6}$ \\ ${ }^{1}$ Department of Music, University of Jyväskylä, Jyväskylä, Finland \\ ${ }^{2}$ Department of Teacher Training, University of Turku, Turku, Finland \\ ${ }^{3}$ Finnish Center of Excellence in Interdisciplinary Music Research, University of Jyväskylä, Jyväskylä, Finland \\ ${ }^{4}$ Centre for Cognitive Neuroscience, University of Turku, Turku, Finland \\ ${ }^{5}$ Cognitive Brain Research Unit, Cognitive Science, Institute of Behavioural Sciences, University of Helsinki, Helsinki, Finland \\ ${ }^{6}$ Department of Psychology, University of Jyväskylä, Jyväskylä, Finland
}

\section{Edited by:}

Lutz Jäncke, University of Zurich,

Switzerland

Reviewed by:

Mireille Besson, CNRS, Institut de

Neurosciences Cognitives de la

Meditarranée, France

Thomas Jacobsen,

Helmut-Schmidt-University, Germany

\section{${ }^{*}$ Correspondence:}

Riia Milovanov, Department of

Teacher Training, University of Turku,

Assistentinkatu 5, Turku 20014,

Finland.

e-mail: riia.milovanov@utu.fi
According to prevailing views, brain organization is modulated by practice, e.g., during musical or linguistic training. Most recent results, using both neuropsychological tests and brain measures, revealed an intriguing connection between musical aptitude and second language linguistic abilities. A significant relationship between higher musical aptitude, better second language pronunciation skills, accurate chord discrimination ability, and more prominent sound-change-evoked brain activation in response to musical stimuli was found. Moreover, regular music practice may also have a modulatory effect on the brain's linguistic organization and alter hemispheric functioning in those who have regularly practised music for years. These findings, together with their implications, will be introduced and elaborated in our review.

Keywords: musical aptitude, linguistic abilities, seashore test, event-related potentials

\section{INTRODUCTION}

Musical training can modulate brain functions in a holistic manner, causing even structural changes in the brain morphology. When comparing adult musicians and non-musicians, differences have been found in the auditory, motor, somatosensory, and visuospatial areas at the cortical level as well as in the cerebellum (Elbert et al., 1995; Pantev et al., 1998; Schneider et al., 2002; Gaser and Schlaug, 2003; Hutchinson et al., 2003; for a review see Jäncke, 2009). In addition to this, musicians seem to possess a larger anterior part of the corpus callosum than non-musicians (Schlaug et al., 1995). Also, several other neural projections appear to be structurally modulated by increased myelinization in musicians (Bengtsson et al., 2005).

As Magne et al. (2006) have pointed out, such structural differences naturally have functional implications. However, it is far from evident how or why these anatomical changes occur. For instance, the role of the age at which practising a musical instrument was initiated and its effects on brain plasticity has not been widely investigated; however, pioneering evidence points out that the younger the subjects begin playing an instrument, the greater are the neuroplastic effects on the brain (Schlaug et al., 1995; Pantev et al., 1998). Correspondingly, it is not yet certain how much the specific demands set up by a given musical genre or instrument can modulate the underlying brain functions (Tervaniemi, 2009).

Neurofunctional accounts of music listening indicate the contribution of a network consisting of fronto-temporal and temporal areas in both the right and left hemispheres. With linguistic functions, the same areas have been shown to be activated with comprehension and production of language. As in music practising, the starting age seems to play a crucial role in foreign language acquisition skills. It is also recognized in foreign language learning that the pronunciation skills are more fluent and better when the second language has been started prior puberty (Johnson and Newport, 1989).

A number of studies indicate an overlap of the behavioral and neural resources between language and music. However, data indicating the lateralization of speech and music functions in the brain hemispheres (and thus differential neural architectures for speech and music) have also been obtained. According to those findings, specific neurocognitive functions intrinsic to music are governed by the right hemisphere and linguistic functions by the left hemisphere (Zatorre et al., 2002; Tervaniemi and Hugdahl, 2003).

Nevertheless, the conceptualization of hemispheric specialization is not straightforward, and the involvement of other higher-order processes, such as memory functions, should also be considered. Any domain-specific process (such as encoding of temporal acoustic properties of speech or a music sound, detecting pitch differences, etc.) also includes the involvement of both long-term and short-term memory functions and, naturally also working memory functions. For instance, linguistic status, context effects, and learning as well as attention can modulate early sensory cortices' functioning, which can therefore effect early processing via top-down effects. In other words, top-down executive processes within auditory pathways may have an important role in explaining the perception processes of speech and music stimuli (Zatorre and Gandour, 2007). Additionally, individual variations must also be borne in mind when discussing brain functioning. 
For instance, different learning strategies could possibly reflect differential involvement of brain organization and may result in different neural representation of the material to be learnt. To sum up, learning and processing musical and linguistic material is composed of different neurofunctional levels with individual variations, ranged from higher to lower order, and each associated with different levels of neural organization.

Only a few studies examine the possible effects of linguistic skills on improving musical skills. It has been shown, though, that speaking Mandarin (which is one of the tonal languages) can help an individual acquire absolute pitch (Deutsch et al., 2006). Very recently, Elmer et al. (2011) asked whether longterm language training influences the functional architecture that supports the discrimination of non-verbal stimulus attributes, and whether such a functional reorganization favors the behavioral performance. They found evidence for a modulation of fronto-parietal brain regions as a function of language expertise and, further, that language training modulates brain activity in those regions involved in the top-down regulation of auditory functions.

In parallel, there is an increasing body of evidence indicating that practising music affects language skills at both the cognitive and neural levels. Magne et al. (2006) tested the hypothesis that musical training facilitates pitch processing not only in music but also in language. Their results show that musician children detected incongruities in both music and language better than non-musician children did. The differences between the two groups of participants were also seen in auditory cortex functioning: early negative components in music and late positive components in language were elicited in musician children, while no such components were present with the nonmusician children. Marques et al. (2007) examined further the effects of musical expertise on pitch perception in a foreign language unknown to the participants. The results showed that adult musicians perceived pitch variations better than non-musicians and that a late positivity developed around $300 \mathrm{~ms}$ earlier in musicians than in non-musicians. Moreno et al. (2009) investigated the effect of musical training on linguistic pitch processing and reading skills. The results showed that musical training not only improved pitch processing in speech but also the reading of irregular words.

The roles of musical aptitude and musical training have recently gained greater attention as a contributing factor in the individual differences in language learning in general (Anvari et al., 2002; Slevc and Miyake, 2006; Tallal and Gaab, 2006; Besson et al., 2007; Marques et al., 2007). Recent results, using both neuropsychological tests and brain measures, revealed an intriguing relationship between musical aptitude and linguistic abilities. These data, acquired in the context of the doctoral thesis project of the first author (Milovanov, 2009), will be introduced and elaborated below. In sum, it was found that individuals with more musical aptitude were better equipped to discriminate phonemic minimal pair contrasts and pronounce second language (English) phonemes than individuals with less musical aptitude. Moreover, the more musical individuals showed enhanced activation in the auditory cortex, reflected by the mismatch negativity (MMN) when compared to less musical individuals.

\section{INTERPLAY BETWEEN MUSICAL APTITUDE AND SECOND LANGUAGE PRONUNCIATION SKILLS: AN EMPIRICAL ENDEAVOR}

The relationship between musical aptitude and linguistic abilities, particularly in terms of second language pronunciation skills and phoneme discrimination skills, was examined in a large project (Milovanov et al., 2008, 2009, 2010; Milovanov, 2009). It consisted of both behavioral and brain measures of Finnish-speaking children (age range 10-12 years) or young adults (age range 2029 years). Based on prior behavioral investigations (Milovanov et al., 2004), the hypothesis was that musical aptitude and linguistic skills would interact both on the attentive and preattentive levels of neurocognitive processing.

Linguistic capacities were determined by Wechsler (1999) or Wechsler (1992), and a pronunciation test, in which English phonemes that are typically difficult for Finnish speakers were read onto a minidisc player after a native speaker model (Milovanov et al., 2008, 2010). A discrimination task of phonemic minimal pairs was also conducted. Moreover, an analogous discrimination task of musical minimal pairs, namely chords that differ slightly in pitch was executed. The musical aptitude test used in our experiments measures the accuracy and threshold of auditory discrimination (Seashore et al., 1960a,b). The test consists of Pitch, Loudness, Rhythm, Time, Timbre, and Tonal memory tasks.

The laterality effects among children and adult groups were investigated by means of a dichotic listening (DL) test (Hugdahl and Andersson, 1986). In DL, two different auditory stimuli are presented to the participant simultaneously, exactly at the same time, one to each ear, by using a set of headphones. Participants are asked to attend to one [Forced-Right (FR) or Forced-Left (FL)], or both of the auditory stimuli and are asked to report what they have heard (Hugdahl, 1998). Here, special attention was paid to FR and FL conditions in order to determine whether these two are differentially affected by musico-linguistic abilities and age (Milovanov et al., 2007).

We also investigated the ability to preattentively discriminate between slight changes in sounds: more specifically, in pitch with regard to music stimuli (Milovanov et al., 2008) and in duration with regard to music and speech stimuli (Milovanov et al., 2009). To this end, event-related brain potentials were performed in accordance with the MMN paradigm. The MMN component of the event-related potentials (ERPs) is an index of the precision which the auditory cortex has when modeling the auditory environment of any listener (Näätänen et al., 2001).

\section{INTERPLAY BETWEEN MUSICAL APTITUDE AND SECOND LANGUAGE PRONUNCIATION SKILLS: NOVEL FINDINGS}

In Milovanov et al. (2010) we compared the relationship between foreign language pronunciation and musical aptitude with three adult test groups of Finnish learners of English: non-musical university students, choir members, and English philology students. The subjects were tested on the production of English phonemes and on a discrimination task of phonemic minimal pairs. Their musical aptitude was determined by the Seashore musicality test. It was found that performance on the English phoneme discrimination test was not connected with their English phonemic production ability. Moreover, the phonemic discrimination ability 
did not differ between the three test groups. Yet, performance on the English pronunciation test was better for subjects with musical aptitude than with less musical aptitude.

In Milovanov et al. (2007), the aim was to determine the effects of age and musical aptitude on phonemic processing in a forced-attention DL paradigm. Subjects differing in musical ability, as tested with the Seashore musical aptitude subtests, listened to consonant-vowel (CV) syllables presented dichotically under three different attention instructions: Non-Forced, FR, and FL conditions. The results showed that musical aptitude and age interacted with the ability to use attention to modulate a bottom-up laterality effect. Only adults who performed well in the Seashore musical aptitude test and practised music regularly showed more accurate left ear monitoring skills when listening to Finnish CV-syllables.

Therefore, based on the result described above, it can be inferred that those subjects with more advanced musical aptitude use the right hemisphere more in language processing in comparison with the non-musical subjects. Also, the musical subjects may possibly pay more attention to the musical components of language than the non-musical subjects.

Milovanov et al. (2008) examined the relationship between musical aptitude and second language pronunciation skills. Twenty children with advanced English pronunciation skills had better musical skills as measured by the Seashore musicality test than 20 children with less accurate English pronunciation skills. The individual Seashore subtests indicated that the participants with advanced pronunciation skills were superior to the participants with less-advanced pronunciation skills in pitch discrimination ability, timbre, sense of rhythm, and sense of tonality. The results in time or loudness subtests did not differ significantly between groups.

The children's ability to produce correct English phonemes with no direct equivalents in Finnish was further determined (Milovanov et al., in preparation). To ensure that all the children had an adequate amount of pretraining in the pronunciation of English, they received an 8-week course of pronunciation training of English including phonemic discrimination exercises (5-7 min/5 times a week, slightly modified from Baker, 1981). Moreover, two behavioral discrimination tests were conducted, both before and after the pronunciation training period. First, the children were required to distinguish the phonemic dissimilarities between English and Finnish through triplets based on minimal pair contrasts of the phonemes, e.g., (a) jeep-jeep-cheap, (b) they-day-they. After that, a standard C-major triad, C, and its two mistuned modifications $\mathrm{C} 2 \%$ and $\mathrm{C} 4 \%$ were investigated following the principles of the phonemic discrimination test.

The advanced pronunciation group outperformed the participants with less-advanced pronunciation skills in terms of a higher number of correct answers and a smaller number of mistakes in both the music and phonemic discrimination tests before and after the training measured by the Error rate. For the less-advanced pronunciation group, triad contrasts were more difficult than the phonemic contrasts both before and after the training. Both test groups marginally improved their phonemic discrimination skills after the training. Interestingly, the training period did not only develop the participants' linguistic skills but also strengthened their discrimination skills for musical sounds, especially in the participants with advanced pronunciation skills.

We also investigated whether children with a more advanced performance in foreign language production represent musical sound features more readily in the preattentive level of neural processing compared with children with less-advanced production skills. Sound processing accuracy was examined by means of ERP recordings. The accuracy of the auditory cortex in representing musical sounds (C-major chord, $\mathrm{C}$, and mistuned C-major chords of $150 \mathrm{~ms}, \mathrm{C} 2 \%$ and $\mathrm{C} 4 \%$ ) was examined by means of ERP recordings in the MMN paradigm. The ERP data accompany the results of the behavioral tests: the advanced pronunciation group showed larger fronto-central MMN with the music stimuli than the lessadvanced pronunciation group. The MMN lateralization pattern did not differ between the test conditions nor the test groups. Taken together, the results could imply that musical and phonemic skills may partly be based on shared neural mechanisms.

In Milovanov et al. (2009) we aimed at specifically comparing the duration discrimination skills between both music and vowel conditions. The subjects were the same as described in Milovanov et al. (2008). The standard speech stimulus consisted of a $250 \mathrm{~ms}$ long monaural recording of the Finnish vowel/ö/and the shorter deviant speech stimulus/ö/with a 150 -ms duration. The music sound was a violin tone $\mathrm{C} 4$, fundamental frequency $261.3 \mathrm{~Hz}$. The standard and deviant durations of the violin tones were equivalent to those of the speech sounds.

The subjects with advanced pronunciation skills and greater musical aptitude were able to preattentively distinguish the duration difference in both conditions more effectively than the lessadvanced pronunciation group with less musical aptitude. Only the advanced pronunciation group showed an MMN lateralization effect: larger MMN amplitudes were found above the right hemisphere, as also in the majority of previous linguistic MMN-studies, in the advanced pronunciation group. Moreover, ERP data show that, irrespective of general musical aptitude, duration changes from 250 to $150 \mathrm{~ms}$ are more prominently and accurately processed in music than in speech sounds. However, one must bear in mind that reducing the duration of speech sounds from 250 to $150 \mathrm{~ms}$ may not necessarily have the same perceptual consequences as reducing the duration of a violin sound by the same amount since speech and music sounds are known to differ in their perceptual attributes (Tervaniemi et al., 2009).

\section{DISCUSSION AND CONCLUSION}

Our review aims at introducing recent evidence about whether musical aptitude could be a crucial factor in learning foreign language pronunciation and discrimination skills. To this end, we introduce empirical evidence about the facilitating role of musical aptitude on foreign language pronunciation acquisition and phonemic and listening discrimination skills. This evidence was obtained from children and adult subjects without any neurological disorders or learning disabilities using various behavioral and brain recording paradigms.

Within the current framework, it seems that music and language are closely related neurocognitive systems (Patel, 2008). Music is one of the oldest, and most basic, socio-cognitive domains of the human species (Koelsch, 2005). Primate vocalizations are 
determined by music-like features, such as pitch, timbre, and rhythm. Fine-grained temporal processing is fundamental to both speech and language (Alcock et al., 2000). Tallal et al. (1991) have already proposed that the underlying deficit which leads to language disturbance is control and processing of timing skills. In addition, Overy (2003) is of the view that musical training develops temporal processing abilities, which are also relevant to phonological segmentation skills. Most recently, Goswami and colleagues have emphasized the role of musical processing for speech processing and the readings skill development: they found a connection between metrical processing, rise-time perception, and reading development in a large sample of normal and dyslexic readers (Huss et al., 2011).

However, the role of possibly shared neural mechanisms between linguistic and musical functions is still unsettled. This is the case even though there is evidence that musical training improves sensory encoding of dynamically changing sounds, which, in turn, helps with linguistic coding. Koelsch (2005) is of the view that the human brain processes music and language with overlapping cognitive mechanisms in overlapping cerebral structures. This view promotes the apparent relationship between music and language which seems to be present from the very early stages of life. Music and language seem to grow from a common source ever since birth, and musical elements aid learning linguistic functions such as sound patterns and meaning (Fernald, 1989) and sound patterns and syntax (Jusczyk and Krumhansl, 1993).

Musical training seems to drive adaptive plasticity in speech processing networks. Kraus and Chandrasekaran (2010) raise an important point that years of processing pitch, duration, and timbre in a fine-grained way in music may enhance their processing in the context of speech. Patel (2011) proposes that music-driven adaptive plasticity in speech processing occurs because five essential conditions are met; there is overlap in the brain networks that process acoustical features used in both speech and music. Moreover, music places higher demands on the networks than does speech, in terms of the precision of processing. The role of positive emotion brought about by musical activities should not be underestimated. In addition to this, practising music requires constant repetition and focused attention. Patel points out that when these conditions are met neural plasticity drives the networks in question to function with higher precision than needed for ordinary speech communication and yet, since speech shares these networks with music, speech processing benefits.

In the present studies, a significant relationship was found between musical aptitude and second language linguistic skills, independent of verbal intelligence. It was discovered that participants with advanced musical aptitude also had advanced foreign language pronunciation skills. Based on the present results, it is proposed that linguistic skills, both in production and discrimination, are interconnected with perceptual musical skills. It is proposed that the musical subjects are able to more efficiently process the musical features in both speech and music, both attentively and preattentively.

The subjects with advanced pronunciation skills and greater musical aptitude were able to preattentively process the duration difference in the vowel and violin sounds more effectively than the less-advanced pronunciation group with less musical aptitude.
Moreover, both triad changes evoked significant MMN responses in both participant groups, although without significant amplitude differences between the groups. Still, the participants with advanced pronunciation skills showed larger fronto-central MMN responses with the $\mathrm{C} 4 \%$ triad condition than the participants with less accurate pronunciation skills. The result could imply that musical and linguistic skills may partly be based on shared neural mechanisms. Alternatively, one could also speculate whether the superior performance in musical and linguistic tasks draws on the same source, namely improved auditory discrimination ability. To illuminate this issue still further, testing of more basic auditory processing skills, not directly related to speech or to music sound listening, should be conducted.

In general, the neurocognitive approach to music and brain processing is still in its infancy. However, the brain research methods still provide us with additional understanding concerning how to relate language and music knowledge to brain function and how phonemic training affects the brain's linguistic and musical organization. The results will give some insight into those neurocognitive mechanisms which are utilized during the task of acquiring a second language or learning to play an instrument. However, results from the current studies suggest that early exposure, even when it is minimal, is of crucial importance in causing neuroanatomical changes. Moreover, even minimal exposure to music practising may help in linguistic functions. The question remains whether certain kinds of reorganization processes of different brain functions, based on constant practise, are possible.

Knowledge regarding the facilitation provided by music in behavioral and neural learning is still quite limited, yet it is recognized. Both musical aptitude and practising may have the capacity to facilitate the learning of academic skills (Schön et al., 2004, 2008; Magne et al., 2006; Besson et al., 2007; Santos et al., 2007). Even if the potential of music in boosting cognitive faculties, other than linguistic ones, such as motor abilities or social skills is recognized, currently the empirical evidence on this is very scarce. Schellenberg and Peretz (2008) point out that the impact of musical training can go far beyond boosting linguistic abilities, extending to more general skills and functions such as working memory, mathematical skills, and spatial abilities.

Based on this, the paradigms in future studies should enable one to differentiate between the underlying factors for the enhancement music is shown to cause in linguistic or other cognitive skills: in the most optimal paradigms, we would learn whether the boosting effects caused by music directly facilitate linguistic and other skills or whether this boosting is actually caused by improved executive functions (attentional skills, working memory; Schellenberg and Peretz, 2008; Besson et al., 2011).

To sum up, the results presented here in this review article provide further evidence that musical aptitude and linguistic skills are interconnected, and that music and language skills are worth examining together. As Patel (2008) puts it, comparing these two domains helps us to explore how the mind makes sense out of sound. More longitudinal studies are needed to resolve the effectiveness of the transfer effects of music skills into other domains. In these endeavors, the participant groups should be matched at the outset with regard to various neural and behavioral measures of auditory processing and tested for linguistic skills before and after musical training. 


\section{REFERENCES}

Alcock, K., Passingham, R. E., Watkins, K., and Vargha-Khadem, F. (2000). Pitch and timing abilities ininherited speech and language impairment. Brain Lang. 75, 34-46.

Anvari, S., Trainor, L., Woodside, J., and Levy, B. (2002). Relations among musical skills, phonological processing, and early reading ability in preschool children. J. Exp. Child Psychol. 83, 111-130.

Baker, A. (1981). Ship or Sheep. An Intermediate Pronunciation Course. New York, NY: Cambridge University Press.

Bengtsson, S., Nagy, Z., Skare, S., Forsman, L., Forssberg, H., and Ullén, F. (2005). Extensive piano practicing has regionally specific effects on white matter development. Nat. Neurosci. 8, 1148-1150.

Besson, M., Chobert, J., and Marie, C. (2011). Transfer of training between music and speech: common processing, attention and memory. Front. Psychol. 2:94. doi:10.3389/fpsyg.2011.00094

Besson, M., Schön, D., Moreno, S., Santos, A., and Magne, C. (2007). Influence of musical expertise and musical training on pitch processing in music and language. Restor. Neurol. Neurosci. 25, 399-410.

Deutsch, D., Henthorn, T., Marvin, E. W., and Xu, H.-S. (2006). Absolute pitch among American and Chinese conservatory students: prevalence differences, and evidence for a speech-related critical period. J. Acoust. Soc. Am. 119, 719-722.

Elbert, T., Pantev, C., Wienbruch, C., Rockstroh, B., and Taub, E. (1995). Increased cortical representation of the fingers of the left hand in string players. Science 270, 305-307.

Elmer, S., Meyer, M., Marrama, L., and Jäncke, L. (2011). Intensive language training and attention modulate the involvement of frontoparietal regions during a non-verbal auditory discrimination task. Eur. J. Neurosci. 34, 165-175.

Fernald, A. (1989). Intonation and communicative intent in mothers' speech to infants: is the melody the message? Child Dev. 60, 1497-1510.

Gaser, C., and Schlaug, G. (2003). Brain structures differ between musicians and non-musicians. J. Neurosci. 23, 9240-9245.

Hugdahl, K. (Ed.). (1998). Handbook of Dichotic Listening. Chichester: John Wiley \& Sons.

Hugdahl, K., and Andersson, L. (1986). The "forced-attention paradigm" in dichotic listening to
CV-syllables: a comparison between adults and children. Cortex 22, 417-432.

Huss, M., Verney, J. P., Fosker, T., Mead, N., and Goswami, U. (2011). Music, rhythm, rise time perception and developmental dyslexia: perception of musical meter predicts reading and phonology. Cortex 47, 674-689.

Hutchinson, S., Lee, L., Gaab, N., and Schlaug, G. (2003). Cerebellar volume of musicians. Cereb. Cortex 13, 943-949.

Jäncke, L. (2009). The plastic human brain. Restor. Neurol. Neurosci. 27, 521-538.

Johnson, J., and Newport, E. (1989). Critical period effects in second language learning: the influence of maturational state on the acquisition of English as a second language. Cogn. Psychol. 21, 60-99.

Jusczyk, P. W., and Krumhansl, C. L. (1993). Pitch and rhythmic patterns affecting infants' sensitivity to musical phrase structure. J. Exp. Psychol. Hum. Percept. Perform. 19, 627-640.

Koelsch, S. (2005). Neural substrates of processing syntax and semantics in music. Curr. Opin. Neurobiol. 15, 1-6.

Kraus, N., and Chandrasekaran, B. (2010). Music training for the development of auditory skills. Nat. Rev. Neurosci. 11, 599-605.

Magne, C., Schön, D., and Besson, M. (2006). Musician children detect pitch violations in both music and language better than nonmusician children: behavioral and electrophysiological approaches. J. Cogn. Neurosci. 18, 199-211.

Marques, C., Moreno, S., Castro, S. L., and Besson, M. (2007). Musicians detect pitch violation in a foreign language better than non-musicians: behavioural and electrophysiological evidence. J. Cogn. Neurosci. 19, 1453-1463.

Milovanov, R. (2009). The connectivity of musical aptitude and foreign language learning skills: neural and behavioural evidence. Anglicana Turkuensia 27, 1-56.

Milovanov, R., Huotilainen, M., Esquef, P. A. A., Välimäki, V., Alku, P., and Tervaniemi, M. (2009). The role of musical aptitude and language skills in preattentive duration determination in school-aged children. $\mathrm{Neu}$ rosci. Lett. 460, 161-165.

Milovanov, R., Huotilainen, M., Välimäki, V., Esquef, P. A. A., and Tervaniemi, M. (2008). Musical aptitude and second language pronunciation skills in school-aged children: neural and behavioral evidence. Brain Res. 1194, 81-89.

Milovanov, R., Pietilä, P., Tervaniemi, M., and Esquef, P. A. A. (2010). Foreign language pronunciation skills and musical aptitude: a study of Finnish adults with higher education. Learn. Individ. Differ. 20, 56-60.

Milovanov, R., Tervaniemi, M., and Gustafsson, M. (2004). “The impact of musical aptitude in foreign language acquisition," in Proceedings of the 8th International Conference on Music Perception and Cognition (ICMPC8), eds S. D. Lipscomb, R. Ashley, R. O. Gjerdingen, and P. Webster (Adelaide: Causal productions).

Milovanov, R., Tervaniemi, M., Takio, F. and Hämäläinen, H. (2007). Modification of dichotic listening (DL) performance by musico-linguistic abilities and age. Brain Res. 1156 168-173.

Moreno, S., Marques, C., Santos, A., Santos, M., Castro, S. L., and Besson, M. (2009). Musical training influences linguistic abilities in 8-year-old children: more evidence for brain plasticity. Cereb. Cortex 19, 712-723.

Näätänen, R., Tervaniemi, M., Sussman, E., Paavilainen, P., and Winkler, I. (2001). "Primitive intelligence" in the auditory cortex. Trends Neurosci. 24, 283-288.

Overy, K. (2003). Dyslexia and music. From timing deficits to musical intervention. Ann. N. Y. Acad. Sci. 999, 497-505.

Pantev, C., Oostenveld, R., Engelien, A. Ross, B., Roberts, L., and Hoke, M. (1998). Increased auditory cortical representation in musicians. Nature $392,811-814$

Patel, A. D. (2008). Music, Language and the Brain. New York, NY: Oxford University Press.

Patel, A. D. (2011). Why would musical training benefit the neural encoding of speech? The OPERA hypothesis. Front. Psychol. 2:142. doi:10.3389/fpsyg.2011.00142

Santos, A., Joly-Pottuz, B., Moreno, S., Habib, M., and Besson, M. (2007). Behavioural and eventrelated potential evidence for pitch discrimination deficit in dyslexic children: improvement after intensive phonic intervention. Neuropsychologia 45, 1080-1090.

Schellenberg, E. G., and Peretz, I. (2008). Music, language, and cognition: unresolved issues. Trends Cogn. Sci. (Regul. Ed.) 12, 45-46.

Schlaug, G., Jancke, L., Huang, Y., Staiger, J. F., and Steinmetz, H
(1995). Increased corpus callosum size in musicians. Neuropsychologia 33, 1047-1055.

Schneider, P., Scherg, M., Dosch, H. G., Specht, H. J., Gutschalk, A. and Rupp, A. (2002). Morphology of Heschl's gyrus reflects enhanced activation in the auditory cortex of musicians. Nat. Neurosci. 5, 688-694.

Schön, D., Boyer, M., Moreno, S., Besson, M., Peretz, I., and Kolinsky, R. (2008). Songs as an aid for language acquisition. Cognition 106, 975-983.

Schön, D., Magne, C., and Besson, M. (2004). The music of speech: music training facilitates pitch processing in both music and language. Psychophysiology 41, 341-349.

Seashore, C. E., Lewis, D., and Saetveit, J. G. (1960a). Seashore Measures of Musical Talents Manual, 2nd Edn. New York: Psychological Corporation.

Seashore, C. E., Lewis, D., and Saetveit, J. G. (1960b). Seashore Measures of Musical Talents CD, Digitally Remastered Version by Esquef, P. (2003). Espoo: Helsinki University of Technology.

Slevc, L. R., and Miyake, A. (2006). Individual differences in secondlanguage proficiency - does musical ability matter? Psychol. Sci. 17, 675-681.

Tallal, P., and Gaab, N. (2006). Dynamic auditory processing, musical experience and language development. Trends Neurosci. 29, 382-390.

Tallal, P., Sainburg, R. L., and Jernigan, T. (1991). The neuropathology of developmental dysphasia: behavioural, morphological, and physiological evidence for a pervasive temporal processing disorder. Read. Writ. 3, 363-377.

Tervaniemi, M. (2009). Musicians same or different? Ann. N. Y. Acad. Sci. 1169, 151-156.

Tervaniemi, M., and Hugdahl, K. (2003). Lateralization of auditorycortex functions. Brain Res. Rev. 43, 231-246.

Tervaniemi, M., Kruck, S., De Baene, W., Schröger, E., Alter, K., and Friederici, A. D. (2009). Top-down modulation of auditory processing: effects of sound context, musical expertise and attentional focus. Eur. J. Neurosci. 30, 1636-1642.

Wechsler, D. (1992). Wechsler Adult Intelligence Scale Revised (WAISR). Helsinki: Psykologien kustannus Oy. 
Wechsler, D. (1999). Wechsler Intelligence Scales for Children, 3rd Edn (WISC-III). Helsinki: Psykologien Kustannus Oy.

Zatorre, R. J., Belin, P., and Penhune, V. B. (2002). Structure and function of auditory cortex: music and speech. Trends Cogn. Sci. 6, 37-46.

Zatorre, R. J., and Gandour, J. T. (2007). Neural specializations for speech and pitch: moving beyond the dichotomies. Philos. Trans. R. Soc. Lond. B Biol. Sci. 363, 1087-1104.

Conflict of Interest Statement: The authors declare that the research was conducted in the absence of any commercial or financial relationships that could be construed as a potential conflict of interest.
Received: 01 April 2011; accepted: 20 October 2011; published online: 21 November 2011.

Citation: Milovanov $R$ and Tervaniemi $M$ (2011) The interplay between musical and linguistic aptitudes: a review. Front. Psychology 2:321. doi: 10.3389/fpsyg.2011.00321

This article was submitted to Frontiers in Auditory Cognitive Neuroscience, a specialty of Frontiers in Psychology. Copyright (c) 2011 Milovanov and Tervaniemi. This is an open-access article subject to a non-exclusive license between the authors and Frontiers Media SA, which permits use, distribution and reproduction in other forums, provided the original authors and source are credited and other Frontiers conditions are complied with. 